HENZ, G.P.; SOUZA, R.M.; PEIXOTO, J.R.; BLUMER, L. Danos causados pelo impacto de queda na qualidade pós-colheita de raízes de mandioquinhasalsa. Horticultura Brasileira, Brasília, v.23, n.4, p.881-886, out-dez 2005.

\title{
Danos causados pelo impacto de queda na qualidade pós-colheita de raízes de mandioquinha-salsa ${ }^{1}$
}

\author{
Gilmar Paulo Henz²; Roberto M. Souza 3 ;José Ricardo Peixoto ${ }^{3}$; Lucimara Blumer ${ }^{4}$ \\ ${ }^{2}$ Embrapa Hortaliças, C. Postal 218, 70359-970 Brasília-DF, E-mail: gilmar@cnph.embrapa.br; ${ }^{3} \mathrm{FAV}$ - Universidade de Brasília, \\ 70910-970 Brasília-DF; ${ }^{4}$ Consultora Estatística, Prodetab/Embrapa.
}

\section{RESUMO}

Como as raízes de mandioquinha-salsa são frágeis e muito suscetíveis a ferimentos, avaliou-se os danos físicos que ocorrem nas raízes devido ao impacto de queda no manuseio pós-colheita e suas consequiências na durabilidade do produto. As raízes foram soltas de duas alturas $(45$ e $90 \mathrm{~cm}$ ) e três posições de queda: horizontal; vertical com "ombro" para baixo (=distal) e para cima (=proximal), simulando-se uma situação comum no beneficiamento e na comercialização. $\mathrm{O}$ experimento foi conduzido em delineamento casualizado com três repetições de 40 raízes por parcela. Após a queda, as raízes foram examinadas individualmente, determinandose os tipos de ferimentos (quebradas, rachaduras, rupturas, lesões superficiais) em relação àquelas aparentemente intactas. A altura de queda afetou diretamente a incidência de injúrias mais graves, como quebras e rupturas. Na queda de $90 \mathrm{~cm}$, a posição de soltura proximal causou $40,7 \%$ de rachaduras, $19,2 \%$ de rupturas e $22,3 \%$ de lesões superficiais; na posição distal causou $45,8 \%$ de rupturas e $23,3 \%$ de quebra nas raízes. Em outro experimento, avaliou-se a respiração, perda de matéria fresca e a deterioração em raízes submetidas à injúria por impacto de queda $(90 \mathrm{~cm})$ e armazenadas a $5^{\circ} \mathrm{C}$ e $24^{\circ} \mathrm{C}$, comparadas com testemunhas não injuriadas, em três repetições $(1,5$ $\mathrm{kg}$ raízes/parcela) distribuídas ao acaso. As raízes submetidas à injúria por queda apresentaram taxas respiratórias superiores em comparação com aquelas intactas quando mantidas na mesma temperatura, e a $24^{\circ} \mathrm{C}$ variou de $15,3 \mathrm{ml} \mathrm{CO} \mathrm{kg}^{-1} \mathrm{~h}^{-1}$ (intactas) a $34,4 \mathrm{ml} \mathrm{CO}$ $\mathrm{kg}^{-1} \mathrm{~h}^{-1}$ (injuriadas). As raízes injuriadas mantidas a $24^{\circ} \mathrm{C}$ apresentaram $84 \%$ de deterioração após quatro dias, enquanto aquelas a $5^{\circ} \mathrm{C}$ não apresentaram deterioração.

Palavras-chave: Arracacia xanthorrhiza, danos mecânicos, lesões, respiração, deterioração.

\begin{abstract}
Damages caused by drop impact on the postharvest quality of arracacha roots

Arracacha roots are very fragile and susceptible to mechanical damage. The postharvest handling system may cause many lesions, mainly by impacts and drops. The effect of drop impact on arracacha roots was simulated in two drop heights $(45$ and $90 \mathrm{~cm})$ and three release positions of the roots (horizontal, vertical distal and vertical proximal). The experiment was carried out in a randomized block design, with three replicates ( 40 roots per and three release positions of the roots (horizontal, vertical distal and vertical proximal). The experiment was carried out in a randomized block design, with three replicates (40 roots per parcel). After the drop, roots were examined individually and the resulting mechanical damage was categorized in four types of lesions (broken, fracture, rupture and abrasion) compared to those apparently undamaged. Drop height affected directly the incidence of more serious mechanical damage, such as broken roots and ruptures. The root position also affected the resulting mechanical damage: roots released from the proximal position at $90 \mathrm{~cm}$ drop height had significantly higher fractures incidence (40.7\%), ruptures (19.2\%) and superficial lesions (22.3\%) than other treatments. At the $90 \mathrm{~cm}$ drop height, roots released from the proximal position had $40.7 \%$ of fractures, $19.2 \%$ of ruptures and $22.3 \%$ of superficial lesions; roots released from the distal position caused $45.8 \%$ of ruptures and $23.3 \%$ of broken roots. The respiration rates and deterioration of arracacha roots submitted to mechanical damage (90 $\mathrm{cm}$ height fall impact) and storage $\left(5^{\circ} \mathrm{C}\right.$ and $\left.24^{\circ} \mathrm{C}\right)$ during four days showed that at the same temperature, mechanically damaged roots had higher respiration rates when compared to sound roots, ranging from $15.3 \mathrm{ml} \mathrm{CO}_{2} \mathrm{~kg}^{-1} \mathrm{~h}^{-1}$ (unbruised) to $34.4 \mathrm{ml} \mathrm{CO}_{2} \mathrm{~kg}^{-1} \mathrm{~h}^{-1}$ (damaged) at $24^{\circ} \mathrm{C}$. Injured roots kept at $24^{\circ} \mathrm{C}$ had $84 \%$ of deterioration after four days, while those kept at $5^{\circ} \mathrm{C}$ were completely sound.
\end{abstract}

Keywords: Arracacia xanthorrhiza, mechanical damage, lesions, respiration, deterioration.

(Recebido para publicação em 17 de Janeiro de 2005 e aceito em 27 de setembro de 2005)

$\mathrm{O}$ produtos hortícolas estão sujeitos a diversos tipos de danos após a colheita, ocasionados por condições inadequadas de manuseio e armazenagem, doenças e injúrias mecânicas. A respiração é o principal processo fisiológico em órgãos vegetais depois da colheita, sendo afetada por diversos fatores, tais como temperatura, composição da atmosfera e estresses químicos, biológicos e físicos (KAYS, 1991; KADER et al.,1992; MORETTI et al.,
2000). No Brasil, não existe uma preocupação muito evidente com a incidência de injúrias mecânicas nos sistemas de manuseio pós-colheita adotados para hortaliças. Entretanto, as consequiências dos danos mecânicos podem ser uma causa primária de perdas nas etapas subseqüentes porque aceleram a taxa de perda de água, levando a um acréscimo na taxa respiratória e diminuição da matéria seca dos produtos (WILLS et al., 1998).
A mandioquinha-salsa é uma hortaliça que apresenta vários problemas pós-colheita, que reduzem substancialmente sua durabilidade e seu valor comercial. Os principais problemas já identificados são a rápida perda de matéria fresca, a ocorrência de podridões e a grande incidência de danos mecânicos (THOMPSON, 1980; AVELAR FILHO, 1989; HENZ, 2001; SOUZA, 2001; SOUZA et al., 2003). Quando comercializadas sem embalagem e/ou

\footnotetext{
${ }^{1}$ Parte da dissertação de mestrado em Agronomia apresentada pelo primeiro autor à Faculdade de Agronomia e Veterinária da Universidade de Brasília
} 
refrigeração, as raízes da mandioquinhasalsa têm duração de apenas um a três dias, dependendo da época do ano e do sistema de manuseio pós-colheita. Quando a perda de matéria fresca ultrapassa $10 \%$, as raízes de mandioquinhasalsa tornam-se murchas e enrugadas, sem valor comercial (AVELAR FILHO, 1989). De acordo com Finger e Casali (1988), a taxa respiratória de raízes de mandioquinha-salsa variou de $3,4 \mathrm{ml}$ $\mathrm{CO}_{2} \mathrm{~kg}^{-1} \mathrm{~h}^{-1}$ após a colheita e alcançou $32,1 \mathrm{ml} \mathrm{CO} \mathrm{kg}^{-1} \mathrm{~h}^{-1}$ após $60 \mathrm{~h}$, possivelmente provocada pela perda de água das raízes. Assim como ocorre para os demais produtos hortícolas, o armazenamento refrigerado também reduz os principais processos fisiológicos das raízes de mandioquinha-salsa, como a respiração, perda de matéria fresca e deterioração (AVELAR FILHO, 1989; HENZ, 1995).

As consequiências de injúrias mecânicas na fisiologia e vida-de-prateleira de algumas hortaliças já estão bem caracterizadas. $\mathrm{O}$ manuseio e a queda de embalagens e frenagens bruscas de caminhões que transportam produtos hortícolas podem ocasionar diferentes tipos de lesões por impacto ou compressão (FAO, 1993; SARGENT et al., 1989a; SARGENT et al., 1989b). Os órgãos vegetais submetidos a vibrações e danos mecânicos em geral aumentam suas taxas respiratórias em comparação com testemunhas sem injúrias (PISARCZYK et al., 1982; SALVEIT et al., 1982; MAO et al., 1995). A severidade e a extensão dos danos mecânicos podem ser afetadas por diversos fatores, sendo os principais (1) a maturidade e o potencial de água; (2) a orientação celular e do tecido no local do impacto; (3) o formato do objeto causador do impacto; (4) a energia com a qual o órgão chocase com o objeto e o respectivo ângulo; e (5) a temperatura da hortaliça no momento da injúria (SARGENT et al., 1992; MILLER, 2003).

A simulação do impacto de queda de raízes de cenoura de quatro cultivares ('Imperator', 'Dominator', 'Cellobunch' e 'Nantes') de quatro alturas $(60 ; 90 ; 120$ e $150 \mathrm{~cm})$ demonstrou que as rachaduras e quebras resultantes variaram de acordo com a cultivar, altura da queda e também da tem- peratura das raízes (CANTWELL et al., 1991). As raízes de cenoura mantidas a $0^{\circ} \mathrm{C}$ apresentaram $70 \%$ de rachaduras em relação àquelas mantidas a $20^{\circ} \mathrm{C}$, que apresentaram somente $15 \%$ (CANTWELL et al., 1991). O efeito de temperaturas mais baixas no aumento dos danos mecânicos também foi comprovado em frutos de morango submetidos à força de impacto, em uma simulação de três alturas de queda $(13 ; 20$ e $38 \mathrm{~cm}$ ) nas cultivares 'Chandler', 'Oso Grande' e 'Sweet Charlie' (FERREIRA et al., 1995). No mesmo trabalho, constatou-se que as forças de compressão causaram maior incidência de injúrias nos frutos (FERREIRA et al., 1995).

Os danos mecânicos em hortaliças têm sido mais extensivamente estudados para a cultura da batata, principalmente devido à mecanização dos processos de colheita, transporte e beneficiamento, que acarretam problemas de perdas no armazenamento. A incidência de injúrias mecânicas em batata aumentou a taxa respiratória em mais de $100 \%$ em todas as cultivares mantidas a $25^{\circ} \mathrm{C}$ (SCHIPPERS, 1977). À medida que os tubérculos passam pelas diferentes etapas do manuseio foi constatado que houve aumento na respiração dos tubérculos (PISARCZYK, 1982). No Brasil, Silva et al. (1993a e 1993b) estudaram o efeito de danos mecânicos de impactos na colheita sobre a taxa respiratória de tubérculos de batata, e as cultivares mais suscetíveis ao impacto aumentaram suas taxas respiratórias significativamente de 10 a $18 \mathrm{ml} \mathrm{CO}_{2} \mathrm{~kg}^{-1} \mathrm{~h}^{-1}$ para 26 a $35 \mathrm{ml}$ $\mathrm{CO}_{2} \mathrm{~kg}^{-1} \mathrm{~h}^{-1}$.

O principal sistema de manuseio pós-colheita da mandioquinha-salsa no Brasil envolve basicamente quatro etapas até alcançar o consumidor, dividindo-se em colheita (1), beneficiamento (2), comercialização no atacado (3) e no varejo (4) (HENZ, 2001). Durante a movimentação do produto nestas diferentes etapas da cadeia de pós-colheita, as raízes de mandioquinha-salsa sofrem vários tipos de danos mecânicos, categorizados como abrasão, ruptura parcial, rachadura e quebra em um trabalho anterior (SOUZA et al., 2003). Neste estudo, o tipo de injúria mais freqüente foi abrasão, na forma de lesões superficiais, alcançando $78,9 \%$ das raízes no varejo, e a etapa em que ocorreu a maior incidência de outros tipos de injúrias mecânicas foi no atacado, onde $7,6 \%$ das raízes apresentaram rupturas, $4,2 \%$ com rachaduras e $10,6 \%$ estavam quebradas (SOUZA, 2001; SOUZA et al., 2003). As principais causas de injúrias mecânicas identificadas no sistema de manuseio pós-colheita da mandioquinha-salsa adotado em São Paulo foram impacto de queda, abrasão e compressão das raízes (SOUZA, 2001; SOUZA et al., 2003).

$\mathrm{O}$ impacto de queda ocorre principalmente durante a movimentação das raízes no galpão de beneficiamento, como na operação de descarga das caixas dos caminhões, colocação das raízes nas redes de lavação e sua transferência para a mesa de seleção e na operação de embalagem. Nos estabelecimentos do varejo, as raízes são transferidas das caixas para as gôndolas, onde também podem ocorrer danos mecânicos por quedas de até $1 \mathrm{~m}$ de altura. A injúria mecânica por abrasão ocorre principalmente pelo atrito das raízes com a superfície das caixas de madeira ou de plástico ocasionada pela vibração durante o transporte por caminhões. A injúria por compressão pode ocorrer pelo empilhamento das caixas de madeira nos galpões de beneficiamento, durante o transporte por caminhões ou nos atacadistas, ocasionado principalmente pelo excesso de raízes nas caixas do tipo "K." A mandioquinha-salsa é uma hortaliça de preço elevado ao consumidor e a manutenção da integridade física das raízes é importante para a valorização desta hortaliça como mercadoria. O objetivo do presente trabalho foi avaliar as consequiências físicas e fisiológicas nas raízes de mandioquinha-salsa submetidas a simulações de injúria mecânica por impacto de queda que ocorrem durante o beneficiamento e a comercialização.

\section{MATERIAL E MÉTODOS}

\section{Simulação do impacto de queda}

Os experimentos foram realizados no Laboratório de Pós-Colheita da Embrapa Hortaliças, em Brasília-DF. O efeito do impacto por queda em raízes de mandioquinha foi avaliado através de 
uma simulação, combinando-se a altura da queda com a posição de soltura das raízes. As alturas de queda utilizadas neste experimento foram definidas de acordo com as alturas do contentor plástico de $34 \mathrm{~kg}$ de capacidade, da mesa de seleção e das gôndolas de exposição da mandioquinha-salsa em supermercados e sacolões. Nestes locais a ocorrência de quedas de raízes é relativamente frequiente e uma das causas mais relevantes de perdas pós-colheita. Raízes de mandioquinha-salsa cv. Amarela Comum das classes $2 \mathrm{~A}$ e $3 \mathrm{~A}$ foram adquiridas na CEASA-DF, selecionando-se para a execução do experimento somente aquelas de tamanho pequeno a médio, com 8-12 cm de comprimento e diâmetro de 2-4 cm, isentas de danos mecânicos e outros defeitos graves (CEAGESP, 2002). O experimento foi conduzido em um delineamento em esquema fatorial $2 \times 3$ (altura $\times$ posição de queda), com três repetições por tratamento (40 raízes/parcela). As raízes foram soltas de duas alturas $(45$ e $90 \mathrm{~cm}$ ) e em três posições de queda: (1) horizontal; (2) vertical proximal, com o "ombro" para cima; (3) vertical distal, com o "ombro" da raiz voltado para baixo. As raízes foram mantidas nas respectivas alturas e posições e deixadas cair livremente sobre um piso plano de cimento rígido e liso. Após a queda, cada raiz foi examinada individualmente, determinando-se os tipos de danos sofridos como rachaduras, quebra, rupturas e lesões superficiais, definidos em um trabalho anterior (SOUZA et al., 2003), e considerando-se também aquelas intactas exteriormente, sem dano aparente.

Avaliação da respiração e da deterioração das raízes

As raízes da cv. Amarela Comum foram adquiridas de um produtor no Núcleo Rural Alexandre Gusmão, em Brazlândia-DF, e transportadas para o laboratório de Pós-Colheita da Embrapa Hortaliças. O experimento foi composto por quatro tratamentos, comparandose raízes intactas com outras submetidas à injúria mecânica por impacto de queda de $90 \mathrm{~cm}$ de altura em uma superfície plana e rígida, e armazenamento posterior em duas temperaturas. Cada tratamento teve três repetições com 1,5

Tabela 1. Significância (teste F) e graus de liberdade (GL) para injúrias resultantes da interação das alturas de queda e posição de soltura das raízes de mandioquinha-salsa.

\begin{tabular}{lcccc}
\hline \multirow{2}{*}{$\begin{array}{l}\text { Fator de } \\
\text { variação }\end{array}$} & \multirow{2}{*}{ GL } & \multicolumn{3}{c}{ Teste F } \\
\cline { 3 - 5 } & & Grave & Leve & Intacta \\
\hline Posição (P) & 2 & $108,55^{* *}$ & $117,76^{* *}$ & $168,65^{* *}$ \\
Altura de queda (A) & 1 & $288,37^{* *}$ & $12,46^{* *}$ & $251,53^{* *}$ \\
P x A & 2 & $11,39^{* *}$ & $36,09^{* *}$ & $127,63^{* *}$ \\
Posição (Altura) & 4 & $59,97^{* *}$ & $76,92^{* *}$ & $148,14^{* *}$ \\
Posição (45 cm) & 2 & $92,45^{* *}$ & $129,37^{* *}$ & $294,00^{* *}$ \\
Posição $(90 \mathrm{~cm})$ & 2 & $27,49^{* *}$ & $24,48^{* *}$ & $2,28 \mathrm{~ns}$ \\
\hline Média $(\%)$ & & 52,36 & 29,44 & 18,06 \\
\hline CV (\%) & & 9,21 & 20,41 & 21,40 \\
\hline
\end{tabular}

** significativo a $1 \%$ de significância; $n s$ = não significativo

kg de raízes em média por parcela, distribuídas ao acaso. As raízes (intactas e injuriadas) foram colocadas em frascos de vidro de 5 litros, e armazenadas às temperaturas de $24 \pm 2^{\circ} \mathrm{C}(75 \%$ UR) e a $5 \pm 2{ }^{\circ} \mathrm{C}(90 \% \mathrm{UR})$. A cada hora foram retiradas amostras das atmosferas internas de cada frasco com seringas e injetadas em um cromatógrafo a gás para leitura da concentração de $\mathrm{CO}_{2}$. Depois de retiradas as amostras os recipientes foram abertos para renovação da atmosfera. Repetiu-se esse procedimento a cada hora, fazendo-se quatro leituras diárias, durante quatro dias. Como padrão utilizou-se $\mathrm{CO}_{2}$ na concentração $1.000 \mathrm{ml} / \mathrm{L}$. Acompanhou-se também a perda de matéria fresca, através de pesagens diárias do material e uma avaliação diária da incidência de deterioração causada por Erwinia sp., considerando-se como deterioradas as raízes que apresentavam uma ou mais lesões de podridão-mole.

\section{RESULTADOS E DISCUSSÃO}

Incidência de injúrias mecânicas causadas por impacto de queda

A simulação do impacto por queda das raízes de duas alturas em uma superfície rígida e plana produziu tipos distintos de injúrias mecânicas. As lesões provocadas pelo impacto de queda foram categorizadas em quatro tipos principais (rachaduras, quebras, lesões superficiais e rupturas) para tornar as avaliações mais rápidas e fáceis de serem executadas. Estes danos mecânicos em raízes de mandioquinha-salsa foram descritos com mais detalhes no trabalho de Souza et al. (2003). As lesões observadas também foram ser separadas pela extensão do dano e importância na aparência do produto em defeitos graves (rachaduras, rupturas e quebras) e leves (lesões superficiais causadas por abrasão), de acordo com a norma de classificação da mandioquinha-salsa proposta pela CEAGESP (2002). As rachaduras caracterizaram-se pelo rompimento parcial da raiz; as quebradas pela separação completa em duas ou mais partes; as rupturas pelo rompimento superficial do tecido, sem destacar-se da raiz; e as lesões superficiais apresentaram remoção parcial da periderme. (SOUZA, 2001; SOUZA et al., 2003). As raízes sem nenhum dano visível externamente foram consideradas como intactas.

Houve interação significativa entre as alturas e as posições de solturas das raízes, que definiu a incidência e a predominância de determinados tipos de injúrias mecânicas (Tabela 1). A altura da queda afetou a incidência dos distintos tipos de danos mecânicos, sendo que as raízes soltas a $90 \mathrm{~cm}$ apresentaram uma predominância de lesões mais graves, como rachaduras, quebras e rupturas. Para todas as posições de soltura das raízes, a porcentagem de raízes com danos mecânicos após a queda foi sempre maior na altura de $90 \mathrm{~cm}$ (Figura 1), situação também observada em raízes de cenoura (CANTWELL et al., 1991) e frutos de morango (FERREIRA et al., 1995).

Na posição de soltura distal (ponta da raiz para baixo), predominaram as lesões mais graves (rachaduras, quebras e rupturas) nas duas alturas (Figura 1), provavelmente devido à força do cho- 


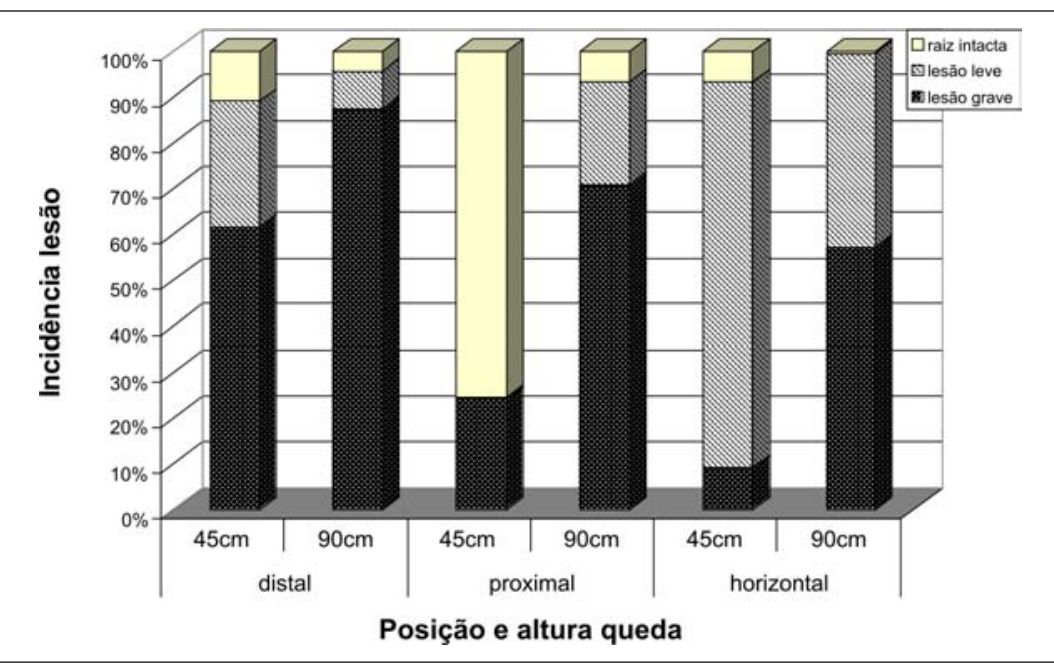

Figura 1. Incidência de injúrias mecânicas leves e graves em raízes de mandioquinha-salsa submetidas a impacto de queda de duas alturas $(45$ e $90 \mathrm{~cm})$ em três posições de soltura (distal, proximal e horizontal). Brasília, Embrapa Hortaliças/FAV-UnB, 2001.

que ocasionado pelo impacto de queda na porção apical da raiz, uma área bem menor que a porção proximal ("ombro"). Para esta mesma posição, nas raízes soltas a $45 \mathrm{~cm}$ de altura predominaram as rachaduras e as rupturas, enquanto a $90 \mathrm{~cm}$ houve maior incidência de rupturas, quebras e rachaduras. $\mathrm{Na}$ posição proximal (ou com o "ombro" da raiz voltado para baixo), constatouse a menor incidência de injúrias mecânicas nas raízes soltas a $45 \mathrm{~cm}$, classificadas como intactas, enquanto a $90 \mathrm{~cm}$ de queda observou-se uma grande incidência de raízes com rachaduras. $\mathrm{Na}$ posição de soltura horizontal, as raízes com queda a $45 \mathrm{~cm}$ apresentaram grande incidência de lesões superficiais, consideradas como menos graves, e as raízes soltas a $90 \mathrm{~cm}$ apresentaram uma tendência de quebra (Figura 1).

De acordo com o trabalho executado em cenoura por Cantwell et al. (1991), a temperatura das raízes apresentou um grande efeito na incidência de rachaduras ocasionadas por impacto de queda, sendo maior nas raízes mantidas a $0^{\circ} \mathrm{C}$ em comparação com àquelas mantidas a $20^{\circ} \mathrm{C}$. Efeito semelhante também foi observado em frutos de três cultivares de morango submetidos a três alturas de queda (FERREIRA et al., 1995). No presente trabalho, a simulação de impacto de queda foi executado em condição ambiental, com a temperatura das raízes variando entre $21^{\circ} \mathrm{C}$ a $23^{\circ} \mathrm{C}$. Nos galpões de beneficiamento da mandioquinha-salsa do estado de São Paulo, as temperaturas das raízes e do ambiente são mais baixas, variando de $15^{\circ} \mathrm{C}$ a $21^{\circ} \mathrm{C}$, dependendo da época do ano (HENZ, 2001). Todo o beneficiamento é executado à noite, geralmente após as $21 \mathrm{~h}$, estendendo-se pela madrugada até o amanhecer. Aágua de córregos da região é geralmente fria, e mantêm a temperatura das raízes mais baixa. Em tese, é provável que as conseqüências de quedas das raízes nesta condição pode provocar danos maiores, principalmente rachaduras. Por outro lado, o armazenamento em baixas temperaturas ainda não é utilizado regularmente para mandioquinha-salsa no Brasil. Caso for necessário, estudos adicionais poderão ser executados com as raízes da mandioquinha-salsa levando-se em consideração alguns fatores importantes que afetam a extensão e a severidade dos danos mecânicos, como o potencial de água, a energia com a qual as raízes chocam-se contra o chão e o respectivo ângulo do impacto, e a temperatura das raízes no momento da injúria (SARGENT et al., 1992; MILLER, 2003).

Respiração de raízes de mandioquinha-salsa

A temperatura mais baixa $\left(5^{\circ} \mathrm{C}\right)$ reduziu significativamente a respiração das raízes de mandioquinha-salsa em comparação àquelas mantidas a $24^{\circ} \mathrm{C}$, e nestas duas temperaturas as raízes injuriadas apresentaram taxas respiratórias mais elevadas em relação às intactas. As raízes mantidas a $5^{\circ} \mathrm{C}$ apresentaram menores taxas de respiração, variando de $3,8 \mathrm{ml} \mathrm{CO}, \mathrm{kg}^{-1} \mathrm{~h}^{-1}$ (intactas) a $8,3 \mathrm{ml}$ $\mathrm{CO}_{2} \mathrm{~kg}^{-1} \mathrm{~h}^{-1}$ (injuriadas), e as raízes mantidas a $24^{\circ} \mathrm{C}$ apresentaram taxas respiratórias que variaram de $15,3 \mathrm{ml} \mathrm{CO}$ $\mathrm{kg}^{-1} \mathrm{~h}^{-1}$ (intactas) a $34,4 \mathrm{ml} \mathrm{CO} \mathrm{kg}^{-1} \mathrm{~h}^{-1}$ (injuriadas) (Figura 2). Temperaturas mais baixas reduzem as taxas respiratórias e de deterioração (WILLS et al., 1998; KAYS, 1991). Finger e Casali (1988) determinaram a taxa respiratória de raízes de mandioquinha que variou de $13,4 \mathrm{ml} \mathrm{CO} \mathrm{kg}^{-1} \mathrm{~h}^{-1}$ após a colheita até $32,1 \mathrm{ml} \mathrm{CO}_{2} \mathrm{~kg}^{-1} \mathrm{~h}^{-1}$, valores próximos aos determinados neste trabalho para a temperatura de $24^{\circ} \mathrm{C}$. As taxas respiratórias foram ajustadas, observando-se uma tendência de redução nas raízes mantidas a $5^{\circ} \mathrm{C}$, com um decréscimo linear naquelas submetidas à injúria por queda $\left(\mathrm{Y}=12,325-1,645 \mathrm{X}, \mathrm{R}^{2}=\right.$ $0,88)$, enquanto as raízes mantidas a $24^{\circ} \mathrm{C}\left(\mathrm{Y}=9,000+4,910 \mathrm{X}, \mathrm{R}^{2}=0,84\right)$, observou-se um aumento linear na taxa respiratória (Figura 2).

Os órgãos vegetais submetidos a vibrações e danos mecânicos em geral aumentam suas taxas respiratórias em comparação com testemunhas sem injúrias (PISARCZYK et al., 1982; SALVEIT et al., 1982; MAO et al., 1995). As raízes de mandioquinha-salsa apresentaram reação semelhante aos de outros produtos hortícolas submetidos a injúrias mecânicas, como tubérculos de batata (SCHIPPERS et al., 1977; PISARCZYK et al., 1982; SILVA et al., 1993a e 1993b), e também aumentaram a respiração quando submetidas ao impacto por queda ou quando armazenadas em temperaturas mais altas. Este aumento na respiração pode estar envolvido no processo de deterioração das raízes assim como na reparação dos tecidos pela suberização de partes superficiais. As condições ideais para acelerar o processo de cicatrização de ferimentos causados por injúrias mecânicas em raízes de mandioquinha-salsa ainda não foram determinadas.

Perda de matéria fresca e deterioração em raízes com injúrias mecânicas

\section{Perda de matéria fresca}

As raízes injuriadas mecanicamente apresentaram maiores taxas diárias de 
perda de matéria fresca (PMF) até quatro dias de armazenamento em relação às raízes intactas nas duas temperaturas avaliadas $\left(24^{\circ} \mathrm{Ce} 5^{\circ} \mathrm{C}\right)$. As raízes injuriadas mantidas a $24^{\circ} \mathrm{C}$ apresentaram $8,3 \%$ de PMF após quatro dias (taxa diária de $2,07 \%$ ), e $6,1 \%$ de PMF para as raízes mantidas a $5^{\circ} \mathrm{C}$, com uma taxa diária de $1,52 \%$. Já as raízes intactas apresentaram as menores perdas de matéria fresca, variando de $4,1 \%$ para aquelas mantidas a $24^{\circ} \mathrm{C}$ a $1,39 \%$ para raízes conservadas a $5^{\circ} \mathrm{C}$, com taxas diárias de $1,02 \%$ e $0,34 \%$, respectivamente. A exposição dos tecidos injuriados provavelmente acelerou a perda de matéria fresca, principalmente porque as umidades relativas dos ambientes eram relativamente baixas para o armazenamento de produtos hortícolas $\left(78 \%\right.$ UR a $24^{\circ} \mathrm{C}$ e $72 \%$ UR a $5^{\circ} \mathrm{C}$ ).

Os dados obtidos no presente trabalho em relação à perda de matéria fresca das raízes estão de acordo com observações empíricas sobre a manutenção da integridade e valor comercial da mandioquinha-salsa quando expostos a granel no varejo. Nesta condição, considera-se que as raízes durem de um a três dias, dependendo da época do ano. Para as raízes de cenoura, considera-se que o máximo de perda de matéria permissível para a manutenção do valor comercial das raízes é de $8 \%$, sendo de apenas 4\% para as raízes mantidas com as folhas (ROBINSON et al., 1975). Dependendo da extensão do dano mecânico nas raízes, a aparência da mandioquinha-salsa pode ficar comprometida depois de apenas dois dias, período em que as lesões tornam-se mais visíveis e facilmente detectáveis. É provável que o limite máximo de perda de matéria fresca para as raízes de mandioquinha-salsa manterem seu valor comercial situe-se em torno de 6-8\%, como já determinado para a cenoura. Acima de $10 \%$ de perda de matéria fresca, as raízes já apresentam danos visíveis de murchamento e perdem seu valor comercial (AVELAR FILHO, 1989).

\section{Deterioração}

As raízes de mandioquinha-salsa tiveram sua conservação pós-colheita comprometida a $24^{\circ} \mathrm{C}$, independente da incidência de injúrias mecânicas. As

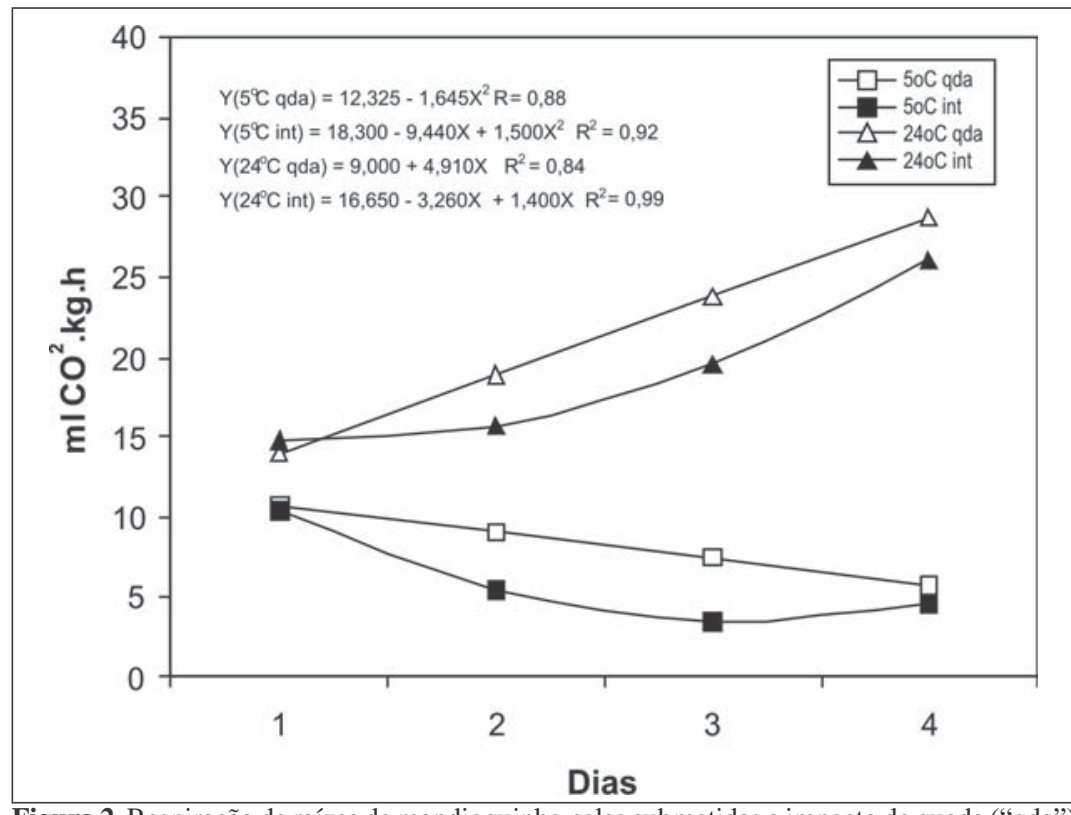

Figura 2. Respiração de raízes de mandioquinha-salsa submetidas a impacto de queda ("qda") em comparação com raízes intactas ("int") armazenadas em duas temperaturas $\left(5^{\circ} \mathrm{C}\right.$ e $\left.24^{\circ} \mathrm{C}\right)$ durante quatro dias. Brasília, Embrapa Hortaliças/FAV-UnB, 2001.

raízes lesionadas e as intactas mantidas a $24^{\circ} \mathrm{C}$ apresentaram deterioração após quatro dias, alcançando $66 \%$ nas raízes intactas e $84 \%$ nas raízes com ferimentos. Já as raízes intactas e com ferimentos mantidas a $5^{\circ} \mathrm{C}$ não apresentaram problemas com deterioração após quatro dias de armazenamento. O efeito benéfico da refrigeração e de embalagens apropriadas para as raízes de mandioquinha-salsa já foi demonstrado anteriormente por outros autores (AVELAR FILHO, 1989; HENZ, 2001), sendo uma excelente tecnologia para a manutenção da qualidade e integridade do produto.

A maior incidência de deterioração nas raízes injuriadas mecanicamente era esperada, uma vez que muitos patógenos pós-colheita são dependentes de portas de entrada para iniciar a infecção, principalmente doenças causadas por fungos. No caso da mandioquinha-salsa, é provável que a bactéria responsável pela podridão-mole permaneça latente nas lenticelas das raízes, iniciando a doença sob condição favorável, como temperaturas acima de $20^{\circ} \mathrm{C}$ e umidade relativa acima de $75 \%$.

De acordo com os resultados obtidos no presente trabalho, a incidência de injúrias mecânicas causadas por impacto de queda em raízes de mandioquinha-salsa deve ser reduzida no manuseio pós-colheita porque afeta a qualidade e a conservação do produto, de modo semelhante ao que já foi observado para outros produtos hortícolas (KAYS, 1991; KADER et al., 1992; WILLS et al., 1998). O tipo predominante de injúria mecânica causada pela simulação do impacto de queda nas raízes de mandioquinha-salsa variou de acordo com a altura da queda, sendo quebra $(48,3 \%)$ para raízes soltas a 90 $\mathrm{cm}$ e lesões superficiais (84\%) para raízes soltas a $45 \mathrm{~cm}$. A incidência de injúrias mecânicas afetou a respiração das raízes de mandioquinha-salsa em relação às raízes intactas a $24^{\circ} \mathrm{C}$ e $5^{\circ} \mathrm{C}$, com tendência a ser mais alta na maior parte do tempo. A perda de matéria fresca foi maior nas raízes injuriadas mecanicamente em relação às raízes intactas a $24^{\circ} \mathrm{C}$ e $5^{\circ} \mathrm{C}$. O uso de embalagens e de refrigeração pode reduzir substancialmente os efeitos negativos da incidência de injúrias mecânicas nas raízes, sendo uma tecnologia simples e apropriada para aqueles produtos com maior valor agregado, como a mandioquinhasalsa produzida no sistema orgânico ou raízes com maior valor de mercado, como as das classes ' $3 \mathrm{~A}^{\prime} \mathrm{e}$ ' $\mathrm{B}$ '. 


\section{LITERATURA CITADA}

AVELAR FILHO, J.A. Estudo da conservação pós-colheita da mandioquinha-salsa (Arracacia xanthorrhiza Bancroft). 1989. 62 f. (Tese mestrado) - UFV, Viçosa.

CANTWELL, M.; MORDEN, G.; RUBATZKY, V.; CHEN, P. Tests to monitor carrot cracking and breaking susceptibility. Eucarpia Meeting on Breeding of Carrots, 1991, Monfavet, France. Eucarpia Carrot 91. Proceedings... Paris: INRA/ Eucarpia, 1991. p.91-103.

CEAGESP. Classificação da mandioquinha-salsa. São Paulo: CQH/CEAGESP, 2002. 8 p. (folder).

FAO. Prevención de perdidas de alimentos postcosecha: frutas, hortaliças y tubérculos. Roma: FAO: 1993. 183 p. (Manual de Capacitación, 14)

FERREIRA, M.D.; SARGENT, S.A.; BRECHT, J.K. Estudo sobre alternativas de manuseio e classificação do morango após a colheita Horticultura Brasileira, Brasília, v.13, n.1, p.82, 1995. Resumo. FINGER, F.L.; CASALI, V.W.D. Determinação da taxa respiratória em mandioquinha-salsa. Horticultura Brasileira, Brasília, v.6, n.1, p.53, 1988. Resumo.

HENZ, G.P. Perdas pós-colheita e métodos de manejo da podridão-mole causada por Erwinia chrysanthemi e Erwinia carotovora spp. em raizes de mandioquinha-salsa. Brasília: Universidade de Brasília, 2001. 255 f. (Tese doutorado).

HENZ, G.P. Métodos de conservação pós-colheita de mandioquinha-salsa. In: V Encontro Nacional sobre Mandioquinha-Salsa. Palestras e trabalhos técnicos... Venda Nova do Imigrante: SOB/ EMCAPA, 1995. p.21-24
KADER, A.A.; KASMIRE, R.F.; MITCHELL, F.G.; REID, M.S.; SOMMER, N.F.; THOMPSOM, J.F. Postharvest technology of horticultural crops. University of California, Berkeley, 1992. 296 p.

KAYS, S.J. Postharvest physiology of perishable plant products. New York: Van Nostrand Reinhold, 1991. $532 \mathrm{p}$

MAO, L.; YING, T.; XI, Y.; ZHEN, Y. Respiration rate, ethylene production, and cellular leakage of fruit following vibrational stree HortScience, v.30, n.1, p.145-149, 1995.

MILLER, A.R Harvest and handling injury: physiology, biochemistry and detection. In: BARTZ, J.A.; BRECHT, J.K. (eds.). Postharvest Physiology and Pathology of Vegetables. New York: Marcel Dekker, 2003. p.177-208.

MORETTI, C.L.; CALBO, A.G.; HENZ, G.P. Metabolismo respiratório na pós-colheita de frutas e hortaliças. Revista Universa, Brasília, v.8, n.1, p.259-274, 2000.

PISARCZYK, J.M. Field harvest damage affects potato tuber respiration and sugar content. American Potato Journal, v.59, p.205-211, 1982.

ROBINSON, J.E.; BROWNE, K.M.; BURTON, W.G. Storage characteristics of some vegetables and soft fruits. Annals of Applied Biology, v.81, p.399-408, 1975

SALVEIT, M.E.; LOCY, R.D. Cultivar differences in ethylene production by wounded sweet potato roots. Journal of the American Society for Horticultural Science, v.107, n.6, p.1114-1117, 1982. SARGENT, S.A.; BRECHT, J.K.; ZOELLNER, J.J. Assessment of mechanical damage in tomato packing lines. Transactions of the ASAE, v.30, n.1, p.630-634, 1989a.

SARGENT, S.A.; BRECHT, J.K.; ZOELLNER, J.J.; CHAU, K.V.; RISSE, L.A. Reducing mechanical damage to tomato during handling and shipment. Transactions of the ASAE, v.30, n.2, p.714-719, 1989b.
SARGENT, S.A.; BRECHT, J.K.; ZOELLNER, J.J. Sensitivity of tomatoes at mature-green and breaker ripeness stages to internal bruising. Journal of the American Society of Horticultural Sciences, v.117, p.119-123, 1992.

SCHIPPERS, P.A. The rate of respiration of potato tubers during storage. Potato Research, v.20, p.173-188, 1977.

SILVA, J.L.O.; CALBO, A.G.; MARTON, L. Efeito de danos mecânicos de impacto na colheita sobre a respiração da batata. Revista Brasileira de Fisiologia Vegetal, Brasília, v.11, n.1, p.106, 1993a. Resumo.

SILVA, J.L.O.; CALBO, A.G.; MARTON, L. Susceptibilidade de cultivares de batata ao escurecimento por impacto. Horticultura Brasileira, Brasília v.11, n.1, p.99, 1993b. Resumo.

SOUZA, R.M. Avaliação da incidência de danos mecânicos na pós-colheita de raízes de mandioquinha-salsa (Arracacia xanthorrhia Bancroft). 2001. 69 f. (Tese mestrado) - Universidade de Brasília, Brasília.

SOUZA, R.M.; HENZ, G.P.; PEIXOTO, J.R. Incidência de injúrias mecânicas em raízes de mandioquinha-salsa na cadeia de pós-colheita. Horticultura Brasileira, Brasília, v.21, n.4, p.712718, 2003.

THOMPSON, A.K. Reduction of losses during the marketing of arracacha (Arracacia xanthorrhiza). Acta Horticulturae, v.116, p.60-65, 1980.

WILLS, R.; McGLASSON, B.; GRAHAM, D. JOYCE, D. Postharvest: an introduction to the physiology and handling of fruit, vegetables and ornamentals. New York: CAB International, 1998. $262 \mathrm{p}$. 